\title{
MANEJO DA FLORA E ORDENAMENTO DO USO PÚBLICO EM ÁREA DE RESTINGA NO DISTRITO DE TAMOIOS, CABO FRIO-RJ
}

ROSEMARY VIEIRA ${ }^{1}$

\section{DOI: $\underline{\text { https://doi.org/10.47977/2318-2148.2021.v9n14p100 }}$}

\section{RESUMO}

São apresentadas ações aplicadas na recuperação e manejo da vegetação de restinga em uma área de preservação permanente na orla sul do Distrito de Tamoios, Cabo Frio, RJ. As atividades se concentraram no cercamento da área, controle de espécies vegetais monodominantes e invasoras, retirada de resíduos e confecção de placas educativas. A espécie monodominante que está sendo retirada é a Dalbergia ecastophyllum (L.) Taub que ocupou a área de forma intensa, limitando o desenvolvimento das outras espécies nativas. Foram identificados também vários indivíduos de espécie Terminalia catappa que apresenta grande potencial invasivo, além da espécie Ipomoea cairica (L.) Sweet que compete com a própria $D$. ecastophyllum. O resultado observado após a supressão é a rápida expansão de outras espécies nativas sobre a área, favorecidas pela biomassa da $D$. ecastophyllum depositada sobre o terreno conservando a sua umidade e nutrientes e protegendo-o da ação dos ventos. A espécie Ipomoea pes-caprae (L.) R.Br, que já ocupava a zona da pós-praia, se expande para o reverso da duna. A realização de um inventário das espécies de flora nas áreas recuperadas é proposta, além de estudos da relação do comportamento da vegetação de restinga com as mudanças climáticas. Desta forma, procura-se contribuir com a proposta de criação, zoneamento e normas de uma Unidade de Conservação que conduza o uso da área e de seu manejo, além da implantação de estruturas físicas necessárias na faixa de vegetação de restinga.

Palavras-chave: Vegetação de restinga; Manejo; Espécie Monodominante; Área de preservação permanente.

\section{FLORA MANAGEMENT AND PUBLIC USE PLANNING IN A COASTAL PERMANENT PRESERVATION AREA, TAMOIOS DISTRICT, CABO FRIO-RJ}

\section{ABSTRACT}

This work presents the applied actions for the recovery and management of coastal vegetation in the Permanent Preservation Area in the southern sector of the District of Tamoios, Cabo Frio/RJ. The activities focused on fencing of the area, controlling monodominant and invasive plant species, removing waste, and making educational signs. The removed monodominant species is Dalbergia ecastophyllum (L.) Taub, which has grown without control that restricts the advancement of other species. Several individuals of the Terminalia catappa species were identified, which have great invasive potential, and Ipomoea cairica (L.) Sweet which compete with D. ecastophyllum. The observed result

\footnotetext{
${ }^{1}$ Professora Associada, Depto de Geografia, Instituto de Geociências, Universidade Federal Fluminense, Email: rosemaryvieira@id.uff.br
} 
after the vegetation suppression is the rapid expansion of other native species that cover the area, favored by the biomass left by D. ecastophyllum, which maintains the moisture and nutrients on the ground and protects it from the wind action. The Ipomoea pes-caprae (L.) R.Br, that occupies the post-beach zone already moves fast toward the reverse of the dune. Future works predict an inventory of flora species in the recovered areas and the possible relationship between vegetation development and climate change. In this way, it aims to contribute to the proposal for the creation, zoning, and norms of a Unit of Conservation that must guide the use of the area and its management, in addition to the implementation of necessary physical structures in the coastal vegetation.

Keywords: Coastal Vegetation; Management; Monodominant Species; Preservation Permanent Area.

\section{INTRODUÇÃO}

Segundo Araújo e Henriques (1984), os ecossistemas de restinga são comunidades vegetais florística e fitofisionomicamente distintas localizadas em terrenos predominantemente arenosos, associadas às variações da linha costa, e por estarem localizadas na interface entre os ambientes marinho e continental, possuem uma fragilidade intrínseca (HOLZER, CRICHYNO e PIRES, 2004). As dunas de areia são um componente integral de sistemas naturais da costa arenosa. As dunas frontais são formações paralelas e próximas a linha da costa formadas pelo transporte eólico de sedimentos oriundos da praia; sofrem diretamente a ação das ondas e a fixação depende do auxílio da vegetação (HESP e WALKER, 2013; DAVIDSON-ARNOTT et al., 2018). Constituem barreiras naturais contra a incursão do mar, inundação, vento, transporte de sedimentos e spray marinho durante as tempestades, o que ajuda a manter a integridade geral dos hábitats da parte interior da praia. Funcionam como a "primeira linha de defesa" da zona costeira contra impactos dos eventos extremos, mais frequentes e intensos, como ressacas e inundações (RUGGIERO et al., 2018; DOYLE et al., 2019) e, ao mesmo tempo, podem disponibilizar sedimentos para a praia a partir da ação das ondas.

A transformação das zonas costeiras com vocação turística pode converter diferentes paisagens em uma única padronizada, diluindo as suas particularidades geográficas e ambientais (MOURA et al., 2015). Tais transformações estão intensificando as consequências das mudanças ambientais globais, que promovem alterações na dinâmica e na frequência de eventos climáticos extremos além da comprovada elevação do nível do mar (IPCC, 2021), promovendo assim um estresse adicional ao sistema ambiental e humano. Desta forma, as condições de permanência da vegetação de restinga, assim como a estabilidade dos sedimentos praiais, podem ser comprometidas.

A Lei Federal $\mathrm{n}^{\circ} 12.651$, de 25 de maio de 2012, estabelece Área de Preservação Permanente - APP: área protegida, coberta ou não por vegetação nativa, com a função ambiental de preservar os recursos hídricos, a paisagem, a estabilidade geológica e a biodiversidade, facilitar o fluxo gênico de fauna e flora, proteger o solo e assegurar o bem- 
estar das populações humanas (Capítulo I, Art. $3^{\circ}$, II). O Art. $4^{\circ}$, VI (Capítulo II, Seção I) considera APP em zonas rurais ou urbanas as restingas como fixadoras de dunas ou estabilizadoras de mangues. O Art. $6^{\circ}$ considera ainda APP, quando declaradas de interesse social por ato do Chefe do Poder Executivo, as áreas cobertas com florestas ou outras formas de vegetação destinadas a uma ou mais das seguintes finalidades: proteger as restingas ou veredas (Capítulo II, Seção I, Art. $6^{\circ}$. II).

Em 2016, por iniciativa de docentes do Departamento de Geografia, Instituto de Geociências, Universidade Federal Fluminense, estabeleceu-se um objetivo norteador de promover a recuperação de parte do cinturão de vegetação de restinga na costa sul do Distrito de Tamoios, Cabo Frio, RJ, considerada uma APP (VIEIRA, MONTEZUMA e VALLEJO, 2019). Desde então, atividades de manejo têm sido empreendidas na área, principalmente na faixa de restinga que abarca o Loteamento Orla 500, afim de propiciar a proteção da linha de costa e da biodiversidade local, estimular a recreação, a pesquisa, a educação ambiental e o uso turístico de forma sustentável na região.

Dois grandes fatores motivaram as atividades de manejo na vegetação de restinga ao longo do Loteamento Orla 500 (VIEIRA, MONTEZUMA e VALLEJO, 2019): o primeiro foi o conhecimento acadêmico sobre o papel fundamental exercido pela vegetação de restinga na estabilização dos sedimentos arenosos costeiros e na proteção da linha de costa. $\mathrm{O}$ segundo aspecto é que as restingas são ambientes naturais muito visados e explorados pelo turismo e atividades de lazer, sujeitos a uma intensa pressão populacional e imobiliária (MARTINS et al., 2012) e aos impactos das intervenções resultantes da ocupação residencial, abertura, pavimentação de acessos e circulação. A crescente quantidade de resíduos deixados pelos usuários e moradores também foi um dos grandes motivadores para o início das atividades de manejo na vegetação de restinga.

O presente estudo apresenta os primeiros resultados das atividades de manejo da vegetação de restinga dentro de uma área de preservação permanente, que cobre o setor costeiro do Loteamento Orla 500, $2^{\circ}$ Distrito de Tamoios, Cabo Frio, RJ.

\section{ÁREA DE ESTUDO}

A área de restinga submetida ao manejo faz parte de uma Área de Preservação Permanente (APP) no setor praiano do Loteamento Orla 500, sul do Distrito de Tamoios, Cabo Frio, com cerca de $25.000 \mathrm{~m}^{2}$. Localiza-se próximo à Estação Radiogoniométrica da Marinha de Campos Novos (ERMCN - 22 $42^{\prime} 36.80^{\prime \prime}$ / $42^{\circ} 00^{\prime} 39.53$ ”O). A principal via de acesso é a rodovia Amaral Peixoto (Fig. 1).

A região de Tamoios consiste em uma planície de restinga e aluvial entre o rio São João (norte) e o rio Una (sul), constituindo um ambiente de sedimentação marinha costeira holocênica de baixo gradiente (SUGUIO, 2003) e com a presença de antigos cordões litorâneos (MARTIN et al., 1997). Predomina o aporte de sedimentos de granulometria média a fina, oriundos principalmente do rio São João, que recobrem as praias entre Barra 
de São João e a Ponta do Pai Vitório, em Búzios, tornando a declividade da antepraia mais suave à medida que se afasta da área-fonte em direção sul (FERNANDEZ e MEUHE, 1998).

O clima na região é classificado como semiárido (COE et al., 2007) com pluviosidade anual em cerca de $854 \mathrm{~mm}$ e temperatura variando entre 20 e $26^{\circ} \mathrm{C}$. A região é marcada por invernos secos e verões chuvosos (LIMA et al., 2020). Eventos de alta energia, como ondas de tempestade (BULHÕES et al., 2016) e maré alta têm impactado não somente o Loteamento Orla 500, como também toda a costa do Distrito de Tamoios, com danos na estrutura física em alguns setores, aumentando, dessa forma, o potencial de risco e vulnerabilidade da área.

Figura 1. Distrito de Tamoios, com a localização dos loteamentos e da Estação Radiogoniométrica da Marinha de Campos Novos (ERMCN).

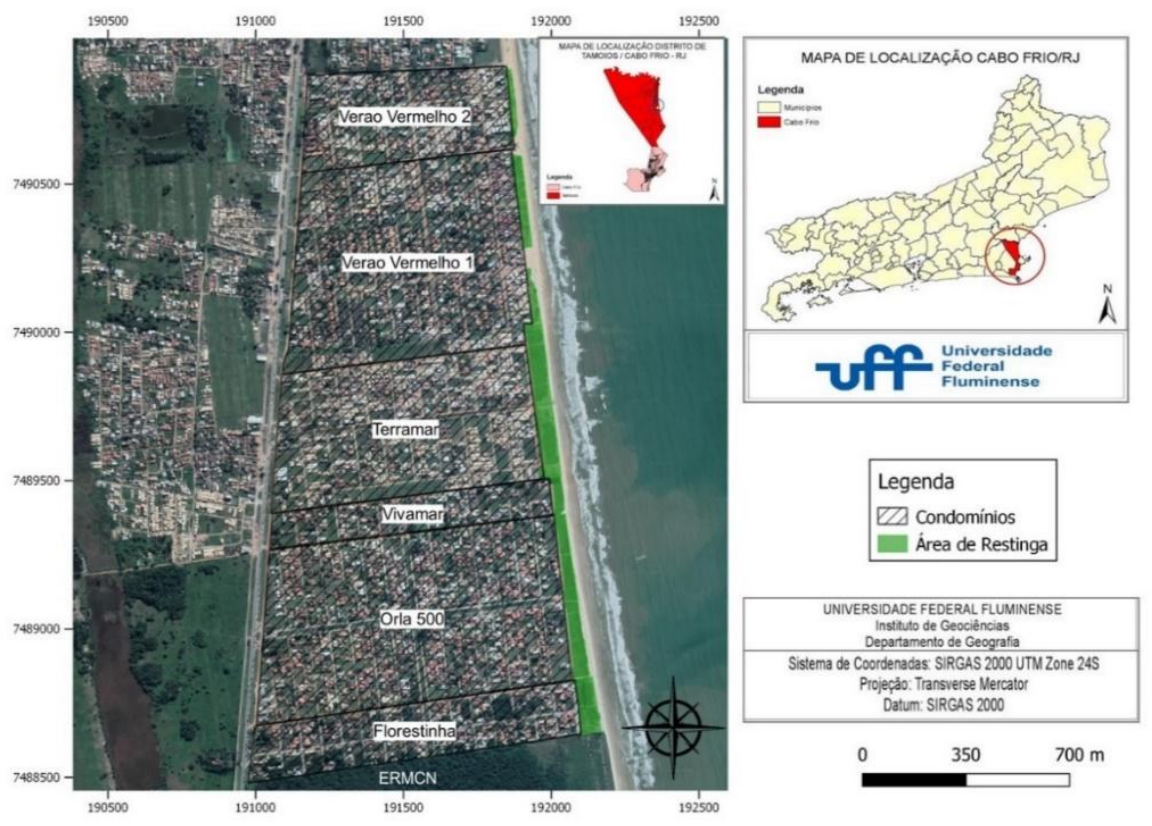

Fonte: Adaptado de Vieira, Chamberlain e Montezuma (2019).

Desde meados dos anos 2000, processos atrelados à variação sazonal da energia dos ventos - direção e intensidade -, amplitude das marés e aporte de sedimentos associados a morfodinâmica da praia (HESP, 2000) têm atuado no transporte eólico regional possibilitado o crescimento da duna frontal no setor sul da costa de Tamoios, do Loteamento Orla 500 à ERMCN (Figs. 2a-b). 
Figura 2. Área da restinga em maio de 2008 (a); duna frontal (outubro de 2021) desenvolvida no mesmo local, (b). Setor central costeiro do loteamento Orla 500, $2^{\circ}$ Distrito de Tamoios, Cabo Frio, RJ.
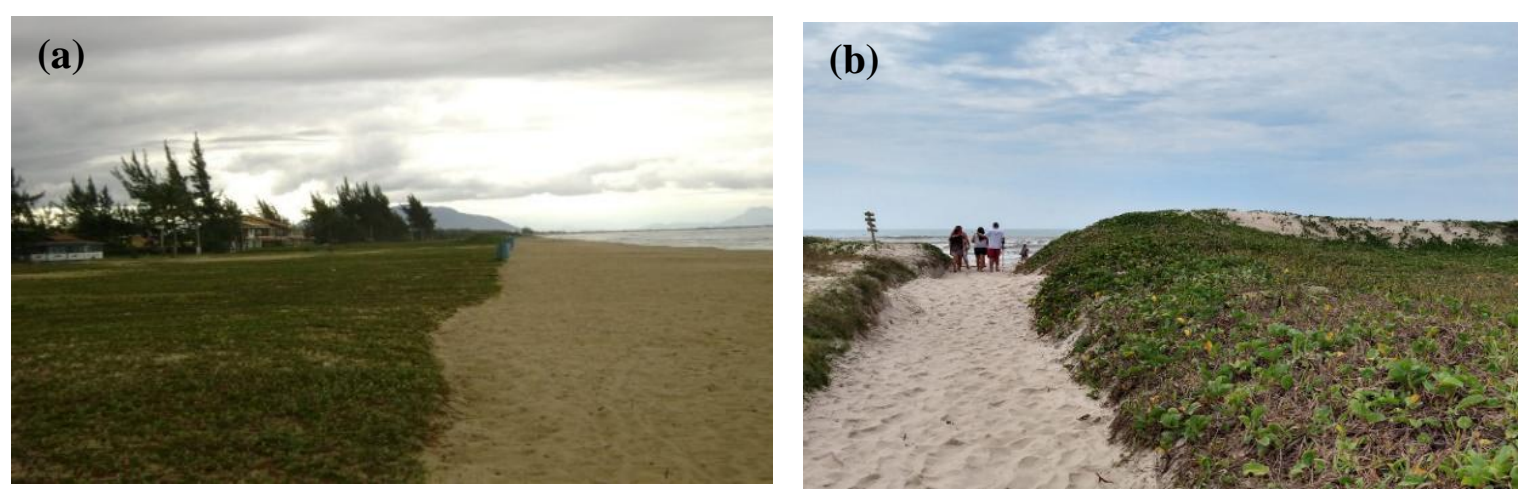

Fonte: Fotos do autor

\section{Sinais de degradação}

A Orla 500 faz parte de um grupo de loteamentos criado na década de 1970, entre o bairro de Unamar e a reserva de Marinha, e que reduziu consideravelmente a área de vegetação de restinga, restringindo-a parcialmente em cinturões litorâneos e em maior concentração na ERMCN, caracterizada pela presença primordial de restinga arbustiva (BOHER et al., 2009). A intensa ocupação da orla do Distrito de Tamoios nas últimas três décadas levou a edificação de imóveis a menos de $50 \mathrm{~m}$ da praia, principalmente nos setores onde a vegetação de restinga foi retirada (Fig. 3 - CASTRO, ROCHA e VIEIRA, 2020). A vegetação de restinga ocupa, atualmente, uma área relativamente contínua, abrangendo os loteamentos Florestinha, Orla 500, Vivamar e Terramar, os mais próximos da Reserva da ERMCN (Figs. 1 e 3).

Contrastando com os outros loteamentos, cuja vegetação de restinga é caracterizada por espécies herbáceas-reptantes, no loteamento Orla 500 algumas espécies se expandiram, formando manchas monodominantes em alguns setores. Essas são assim definidas quando compostas por uma única espécie com mais de 50\% de dominância (cobertura, área basal, biomassa) (HART et al., 1989). A espécie em expansão passou a cobrir a área e os resíduos lançados pelos usuários da praia sobre a vegetação. Houve várias tentativas prévias às ações de manejo de implantação de locais apropriados para a instalação de coletores. No entanto, tais coletores transformaram-se em pontos de concentração de resíduos além da sua capacidade (Fig. 4), utilizado tanto pelos frequentadores como pelos próprios moradores, que passaram a depositar também os seus resíduos domésticos. 
Figura 3. Evolução da ocupação do solo no Distrito de Tamoios nos anos 1970, 2005 e 2018. A área vegetada ao sul corresponde a ERMCN.

\section{Classificação Visual da Orla Marítima (Cabo Frio, RJ)} (1970;2005;2018)

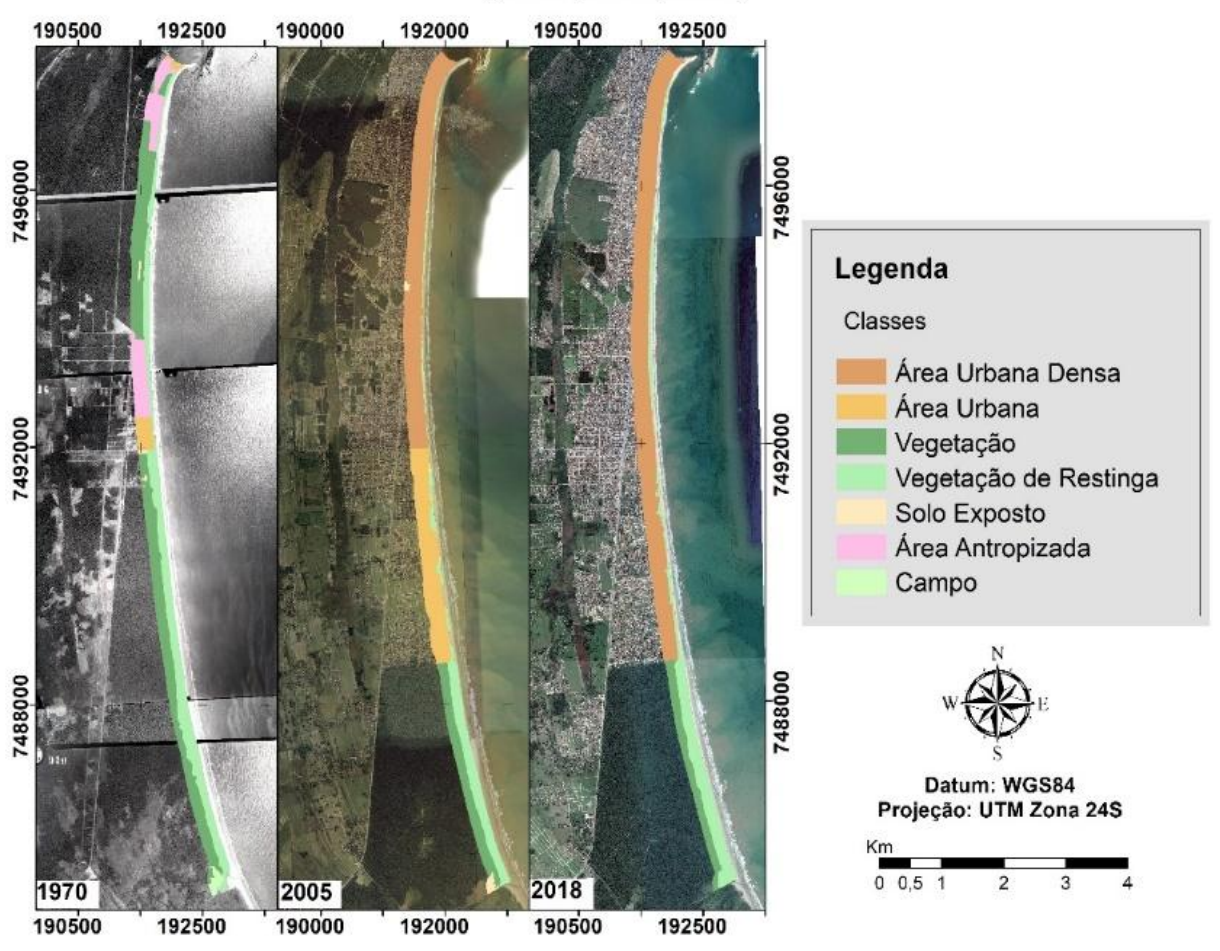

Fonte: CASTRO, ROCHA e VIEIRA, 2020

Figura 4. Coletores de lixo junto a vegetação não comportando a quantidade de resíduos. Setor costeiro do loteamento Orla 500, $2^{\circ}$ Distrito de Tamoios, Cabo Frio, RJ

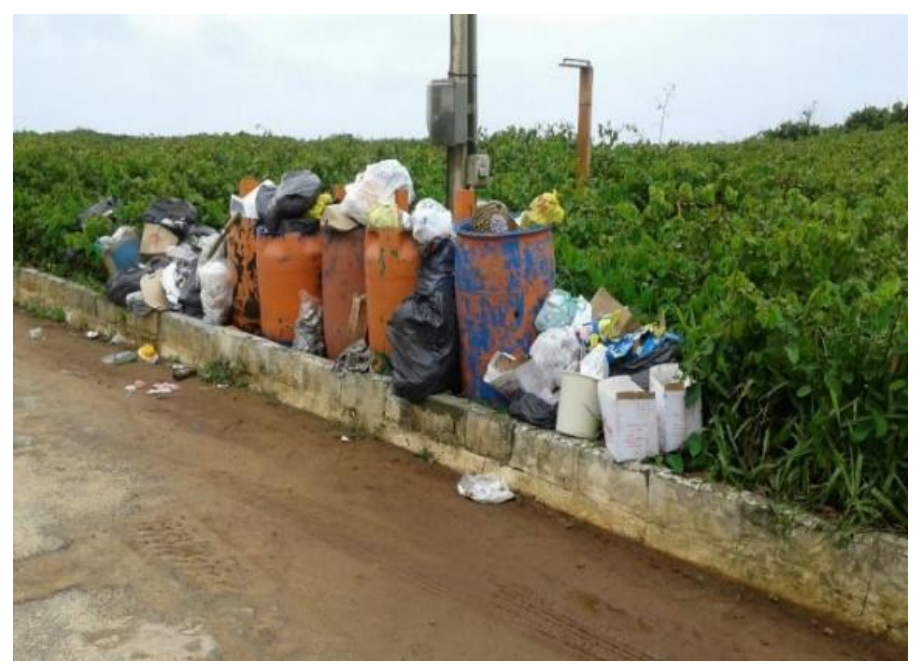

Fonte: Fotos do autor 


\section{Atividades introdutórias de manejo}

Uma das primeiras atividades empreendidas antes do trabalho de manejo foi o levantamento preliminar das espécies vegetais presentes na restinga, avaliando as condições de cobertura e conservação. A princípio, o trabalho foi realizado com apoio de especialistas e alunos convidados que elaboraram uma listagem contendo a indicação das famílias botânicas, nome científico e nome vulgar (Quadro 1). Em seguida, o uso de imagens de satélite e de drone propiciou estimar a extensão de cobertura da vegetação no loteamento e a produção de registros panorâmicos paralelos à linha da costa, que ajudaram na observação das características locais da ocupação humana.

Paralelamente, foram dinamizadas ações que contribuíssem para as mudanças da percepção ambiental sobre a restinga e sua importância para as comunidades locais. Esta tarefa ainda é uma das mais difíceis, considerando a impossibilidade de manutenção de contato permanente com os frequentadores e usuários, agravada com o início da pandemia de COVID-19 em 2020. Neste caso, a estratégia concentrou-se na montagem de cartazes e placas educativas em locais bem visíveis e de fácil acesso. Iniciativas adicionais estabelecendo os limites de acesso, como no caso das trilhas fisicamente demarcadas, tiveram a função de ordenar a movimentação de pessoas e as atitudes adequadas no ambiente de restinga. A divulgação dos trabalhos e a solicitação de materiais é feita pelas mídias sociais.

Em adição, foi elaborada uma primeira estimativa da capacidade de carga física das praias desse setor, afim de garantir o serviço ecológico oferecido pela vegetação de restinga, sem deixar de atender a demanda de conforto e de infraestrutura de moradores, veranistas e visitantes. $\mathrm{O}$ trabalho aplicou metodologias de avaliação da capacidade de suporte das praias junto aos loteamentos Florestinha, Orla 500, Vivamar, Terramar e Verão Vermelho (Fig. 1), a fim de subsidiar o poder público nos planos de uso e de ocupação do solo em uma área que sofre a ameaça da erosão costeira. Os resultados podem ser vistos em Vieira, Chamberlaim e Montezuma (2019).

\section{Domínio da espécie Dalbergia ecastophyllum (L.) Taub.}

Durante os levantamentos iniciais de identificação de espécies (Quadro 1), foi observada a presença de espécies herbáceas e subarbustivas. No entanto, foi verificada claramente no Loteamento Orla 500 a rápida expansão e domínio da espécie $D$. ecastophyllum, conhecida popularmente como rabo de bugio, e que ocorre naturalmente em áreas de restinga e de manguezal. Infere-se que a rápida expansão dessa espécie possa estar vinculada a retirada da vegetação natural de restinga no loteamento para a implantação de áreas de recreação nos anos 1990-2000 (Figs. 5a-b). Como não houve manejo após a sua desativação, a $D$. ecastophyllum se desenvolveu sem controle em uma nova área de colonização e passou a competir e a dominar outras espécies nativas na sucessão ecológica, principalmente no setor do reverso da duna frontal em crescimento, ficando assim protegida 
da ação de ventos e da salinidade. Por outro lado, a própria D. ecastophyllum passou também a sofrer em alguns setores o domínio de outras espécies, em especial da Ipomoea cairica (L) Sweet, como mostram as Figuras 6a-b. Ademais, a altura desenvolvida pela vegetação já superando os 2 metros, o que aumentou a sensação de insegurança por parte dos moradores e frequentadores, alimentando o argumento de que o isolamento visual da praia a tornaria mais suscetível a ataques e assaltos (Fig. 7a).

Quadro 1. Lista de espécies inicialmente identificadas na área de restinga.

\begin{tabular}{|l|l|}
\hline ARECACEAE & \\
\hline Allagoptera arenaria (Gomes) Kuntze & Guriri \\
\hline AMARANTHACEAE & \\
\hline Alternanthera maritima (Mart.) St.-Hil & \\
\hline ARALIACEAE & \\
\hline Hydrocotyle boranienses Lam & Erva-capitão \\
\hline CACTACEAE & \\
\hline Opuntia arechevaletai Spegazzini ex Arechevaleta & \\
\hline Cereus fernambucensis Lem. & Mandacaru-da-praia \\
\hline CONVOLVULACEAE & \\
\hline Ipomoea imperati (Valhl) Griseg & Cipó-da-praia, Campainha-branca \\
\hline Ipomoea pes-caprae (L.) R. Brown & Batata-da-praia, Pé-de-cabra \\
\hline CYPERACEAE & \\
\hline Remirea maritima Aubl & Pinheirinho \\
\hline FABACEAE & \\
\hline Canavalia rosea (Sw.) & Feijão-da-praia \\
\hline Dalbergia ecastophyllum (L.) Taub. & Rabo-de-Bugio \\
\hline Sophora tomentosa L. & Feijão-da-praia, cambuí-da-restinga \\
\hline POACEAE & \\
\hline Panicum racemosum (P. Beauv.) Spreng. & Grama-da-praia \\
\hline Paspalum vaginatum Sw. & Grama-da-praia \\
\hline
\end{tabular}

Fonte: Vieira, Montezuma e Vallejo (2019).

A área de ocorrência da D. ecastophyllum é ampla em escala global, com registros nos EUA, Porto Rico e Cuba, além da costa ocidental da África, e corresponde à toda zona costeira do Brasil (CARVALHO, 1997). A espécie se apresenta com arbustos entrelaçados com ramos escandentes, folhas unifoliares e pequenas flores brancas. É um arbusto típico de vegetações de transição entre dunas e restinga, associada a estuários e manguezais, onde seu hábito semi- prostrado e de caule múltiplo ajuda na estabilização da areia e recuperação de áreas degradadas, sendo ainda encontrada menos frequentemente em vegetação seca de restinga ou em solos arenosos como um arbusto robusto ou uma árvore pequena (CARVALHO, 1997). 
Figura 5. Retirada da vegetação natural em alguns setores (a) e posterior sucessão secundária e domínio da espécie D. ecastophyllum (b). Setor costeiro do loteamento Orla 500, $2^{\circ}$ Distrito de Tamoios, Cabo Frio, RJ.
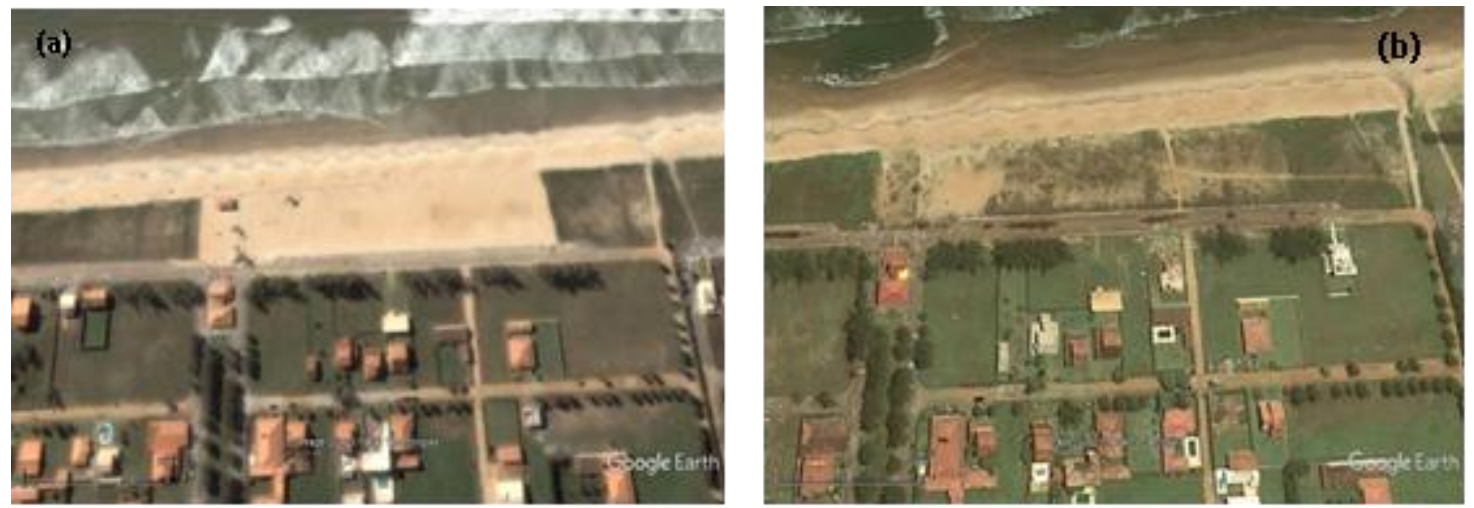

Fonte: Google Earth 2004 (a) e 2009 (b)

Figura 6a-b. Domínio da espécie I. cairica sobre a D. ecastophyllum. Setor costeiro do loteamento Orla 500, $2^{\circ}$ Distrito de Tamoios, Cabo Frio, RJ.
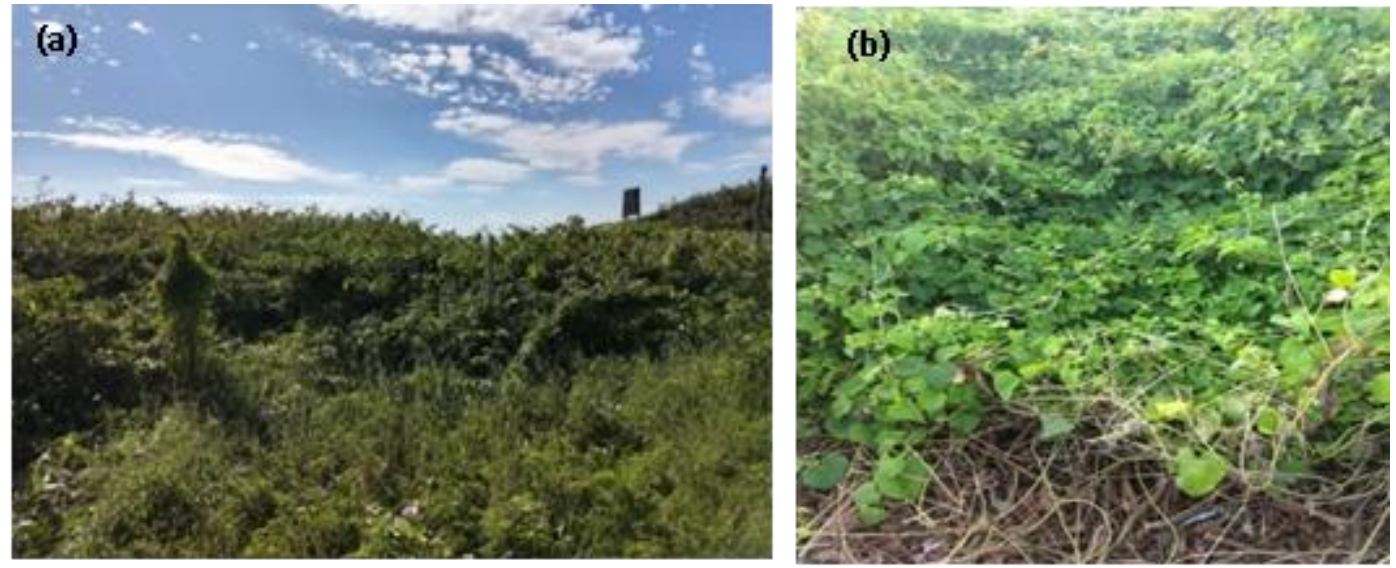

Fonte: Fotos do autor

Devido ao padrão de distribuição da espécie no ambiente ao formar um emaranhado bastante sombreado (Fig. 7b), as áreas ocupadas pela D. ecastophyllum podem registrar uma perda de riqueza e diversidade de espécies. O sombreamento proporcionado pela $D$. ecastophyllum pode influenciar negativamente o crescimento de espécies heliófilas, dificultar a germinação pela formação de uma espessa camada de galhos ou até competir por recursos (SOUZA, 2010). A espécie D. ecastophyllum é um exemplo de planta dominante na vegetação adjacente às dunas (MARQUES e DULEBA, 2004) e, uma vez que suas sementes são dispersadas pelo mar e pelo vento, há um grande aporte de sementes sobre as dunas (CARVALHO, 1997). No entanto, a própria ação das ondas pode remover as sementes caso não haja um local para ela se fixar, o que faz do reverso da duna o ambiente mais favorável ao seu crescimento e expansão. 
Figura 7. Expansão e domínio da espécie rabo-de-bugio (D. ecastophyllum) sobre a vegetação: altura dificultando a visão da praia (a); poucas mudas se desenvolvendo sobre a ocupação por D. ecastophyllum para a expansão de outras espécies (b). Setor costeiro do condomínio Orla 500, $2^{\circ}$ Distrito de Tamoios, Cabo Frio, RJ
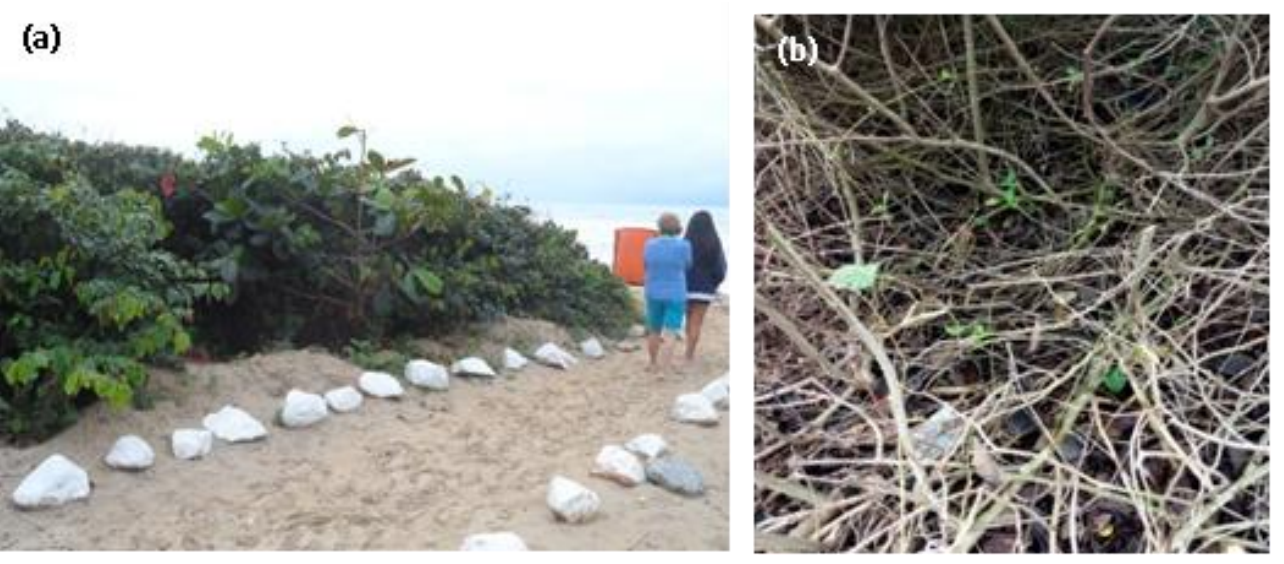

Fonte: Fotos do autor

\section{METODOLOGIA}

Foi realizado levantamento bibliográfico usando palavras-chave na base de dados Periódicos Capes, Scielo e Web of Science sobre atividades de manejo em vegetação de restinga, em especial, referentes às espécies D. ecastophyllum, Ipomoea pes-caprae (L.) R. Brown, e espécies invasoras, além de descrições das características ambientais que subsidiaram previamente a realização das atividades de manejo.

Com respeito a área de vegetação de restinga, as áreas envolvidas no manejo foram divididas em 5 parcelas ordenadas no sentido sul-norte (Fig. 8 e Quadro 2) e ações se concentraram em três metas: (a) recuperação de áreas degradadas; (b) remoção de espécies exóticas; (c) controle das espécies dominantes. Considerou-se a princípio o plantio de espécies nativas de restinga nas áreas de supressão. No entanto, a presença da espécie $I$. pes-caprae no setor pós-praia possibilitaria o avanço dessa espécie sobre a duna e para o setor reverso da duna (Fig. 9), porque além da sua eficiente propagação vegetativa, ela aloca considerável quantidade de recursos para produção de um grande número de sementes, importantes na ocupação de dunas recém-formadas (CASTELLANI e SANTOS, 2006). A I. pes-caprae é encontrada logo após a linha de maré alta (Fig. 9), a partir da qual sofre menos perturbações pela invasão das marés de tempestade e soterramentos (DEVALL, 1987).

As atividades foram divididas em duas fases: (1) poda e recuo da espécie $D$. ecastophyllum para junto da duna frontal em alguns setores, com o objetivo de ampliar a área de ocupação das outras espécies. Essa fase foi efetuada ao longo de 2018 e 2019; (2) supressão da espécie D. ecastophyllum em alguns setores junto a duna frontal para a ocupação e expansão de outras espécies, em especial, a I. pes-caprae, já estabelecida no setor pós-praia. Essa fase começou em maio de 2020 e segue em andamento. A supressão 
da espécie D. ecastophyllum no Loteamento Orla 500 foi efetuado de forma lenta para que outras espécies nativas, como a I. pes-caprae, se distribuíssem sobre o terreno. Dentro da recuperação de áreas degradadas, incluiu-se também o recolhimento dos resíduos acumulados. Todos os trabalhos foram e são realizados de forma voluntária, sendo o recolhimento do material verde efetuado pela administração do Loteamento Orla 500.

Figura 8. Áreas da vegetação de restinga divididas em parcelas com atividades de manejo.

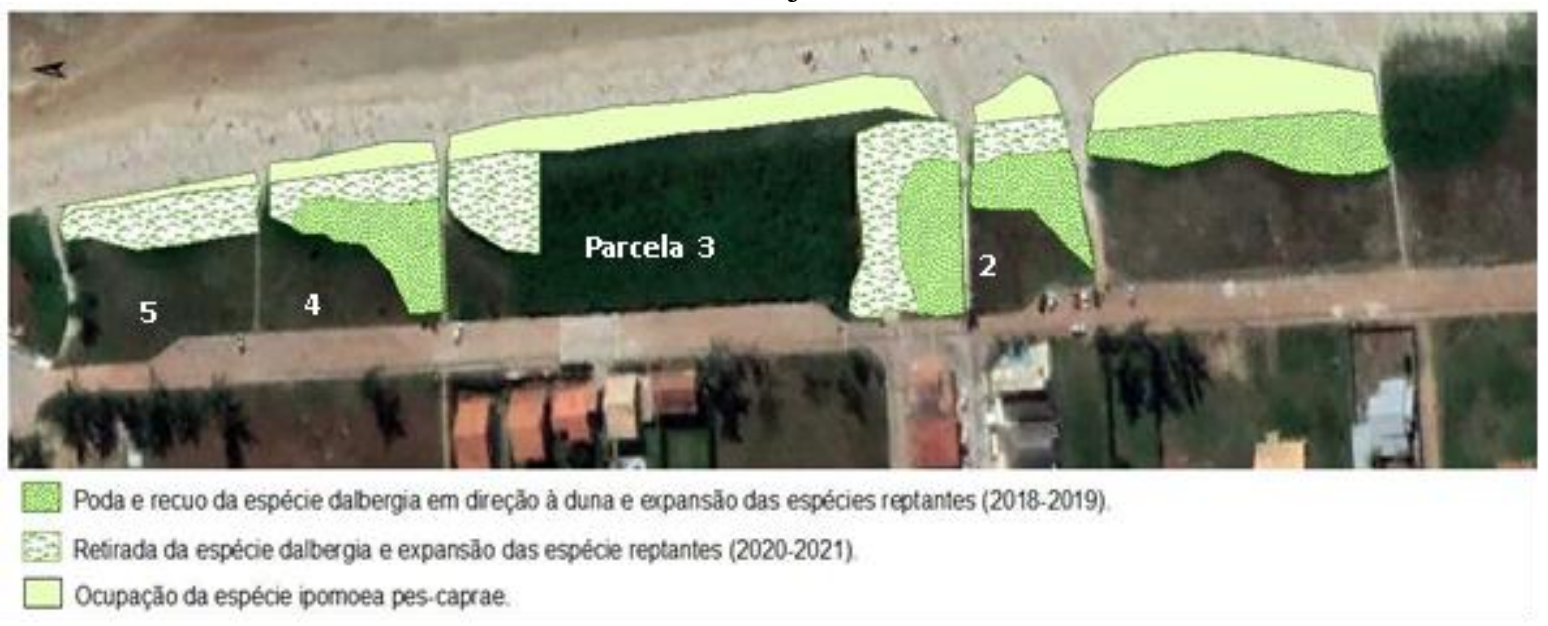

Quadro 2. Dimensões das parcelas de vegetação de restinga trabalhadas.

\begin{tabular}{|c|c|c|c|}
\hline Loteamento & Id. & Área $\left.\mathbf{( m}^{\mathbf{2}}\right)$ & Perímetro $(\mathbf{m})$ \\
\hline Orla 500 & Parcela 1 & 3.642 & 260 \\
\hline Orla 500 & Parcela 2 & 1.260 & 140 \\
\hline Orla 500 & Parcela 3 & 5.853 & 390 \\
\hline Orla 500 & Parcela 4 & 1.706 & 170 \\
\hline Orla 500 & Parcela 5 & 1.712 & 180 \\
\hline
\end{tabular}

Figura 9. Ocupação na parcela 4 da I. pes-caprae no setor pós-praia (voltada para o mar) e da D. ecastophyllum no setor reverso da duna (voltada para o loteamento). Setor costeiro do loteamento Orla 500, $2^{\circ}$ Distrito de Tamoios, Cabo Frio, RJ

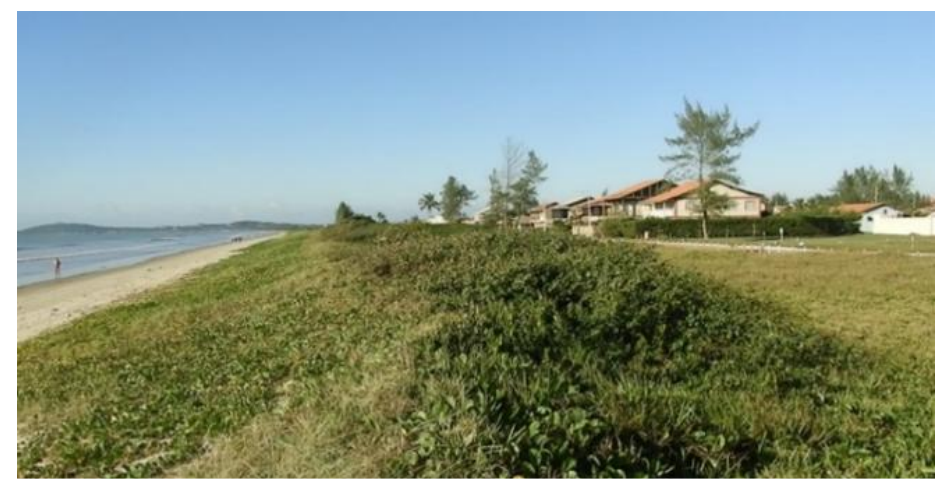

Fonte: Foto do autor 


\section{RESULTADOS}

\section{Manejo - $1^{\circ}$ Fase (2018-2019)}

Na primeira fase, a D. ecastophyllum foi apenas podada em suas extremidades que alcançavam a Av. Litorânea e os caminhos de acesso à praia (Figs. 10a-b). Contudo, o rápido crescimento da vegetação fez essa tarefa ineficaz. Decidiu-se, portanto, retirá-la e mantê-la junto a duna como forma de proteção. Mesmo assim, outras espécies dominantes e invasoras, em especial a I. cairica, mantiveram seu avanço sobre a vegetação herbáceareptante e sobre a própria $D$. ecastophyllum, descaracterizando a cobertura vegetal típica de restinga (Figs. 6a-b). Em adição, a grande quantidade de resíduos encontrados sob e entre a vegetação ratificou a situação de risco da presença de animais peçonhentos, também identificados durante os trabalhos.

Para preservar a área de manejo da circulação de pessoas, foi feito o cercamento da faixa voltada para o interior do loteamento (Av. Litorânea) e a confecção de placas educativas a partir de doações e de campanhas de arrecadação (Figs. 11a-b).

Figura 10. Poda das extremidades da D. ecastophyllum (a) e seu rápido crescimento (b). Setor costeiro do loteamento Orla 500, $2^{\circ}$ Distrito de Tamoios, Cabo Frio, RJ.
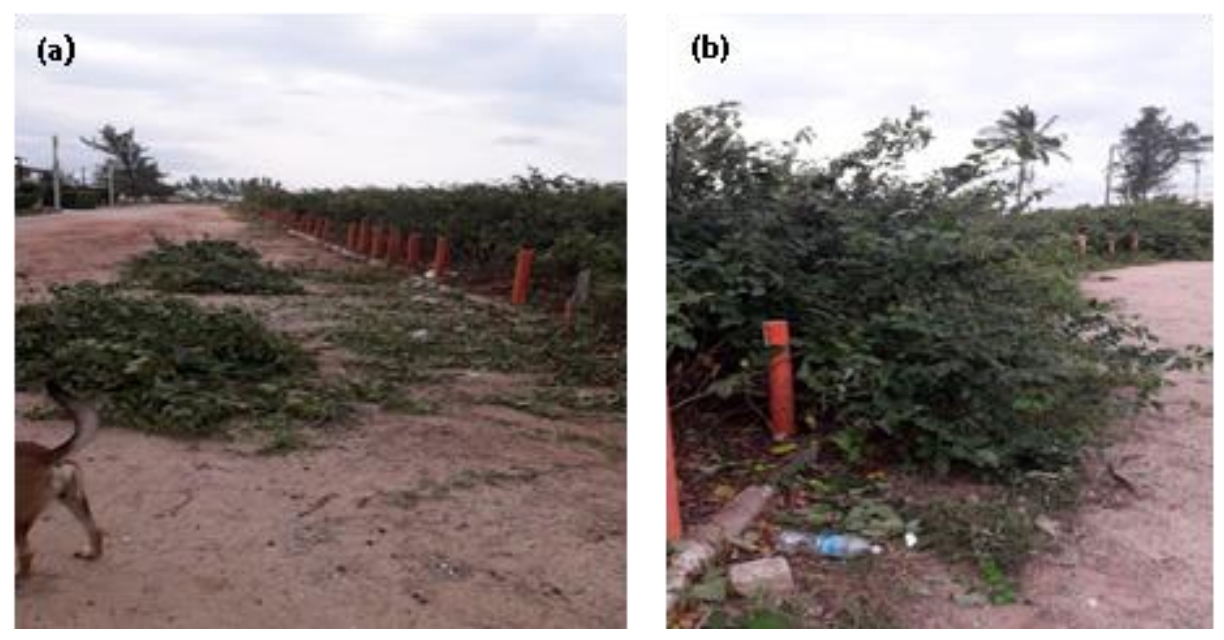

Fonte: Fotos do autor 
Figura 11. Cercamento da área de restinga junto à Av. Litorânea (a) e instalação de placas educativas (b). Setor costeiro do condomínio Orla 500, $2^{\circ}$ Distrito de Tamoios, Cabo Frio, RJ.
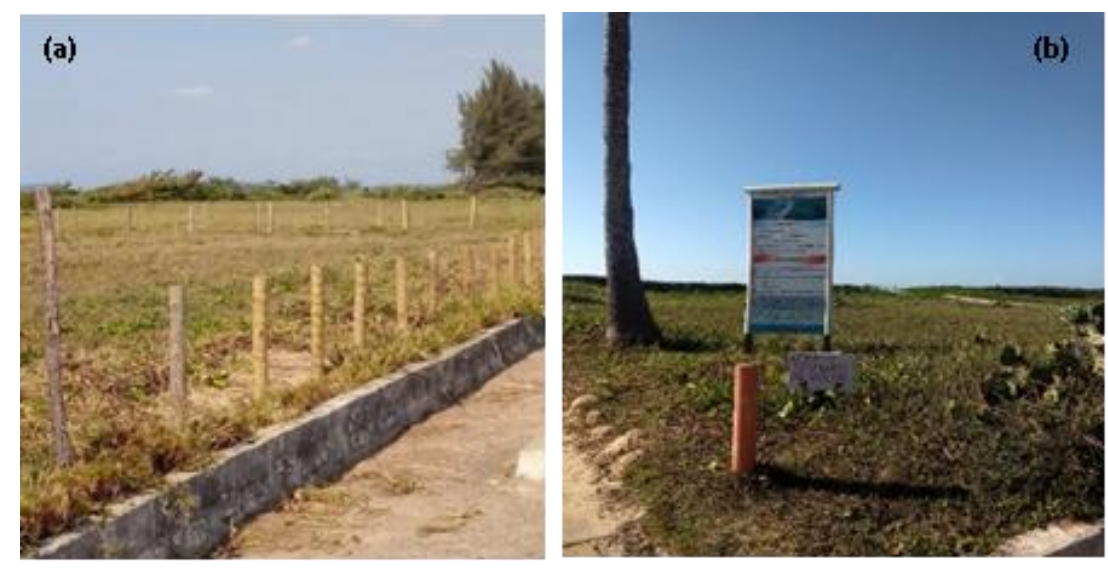

Fonte: Fotos do autor

\section{Manejo $-2^{\circ}$ Fase $(2020-$ em andamento $)$}

Essa fase é caracterizada pela supressão da espécie D. ecastophyllum no setor reverso da duna em algumas parcelas para dar espaço ao avanço das outras espécies. Suas raízes, distribuídas horizontalmente e ramificadas, exigem um trabalho meticuloso e demorado. Seus galhos e folhas são recolhidos e triturados para a produção de adubo. As amendoeiras (Terminalia catappa) também são podadas ao máximo para posterior supressão.

A seguir são apresentadas as atividades de manejo nas parcelas (Fig. 8 e Quadro 2).

\section{Parcela 1}

Nesta parcela, o trabalho realizado no período 2017-2018 foi o de manter a espécie $D$. ecastophyllum junto à duna. Devido às atividades efetuadas nas outras parcelas, a supressão da espécie não foi ainda iniciada.

\section{Parcela 2}

Na parcela 2 (Fig. 8, Quadro 2 e Figs. 12a-e), a D. ecastophyllum foi totalmente retirada nas duas fases entre os anos 2018 e 2020. No período 2018-2019, a espécie foi "empurrada" e mantida junto a duna frontal (Fig. 12a). Em 2020, a supressão se efetuou de junho a novembro, de forma a permitir a expansão das outras espécies aproveitando as condições do terreno. Foi adotada em todas as parcelas a manutenção sobre o terreno da cobertura da biomassa da espécie retirada de forma a proteger o solo da ação constante do vento e, mantendo ao mesmo tempo a umidade e nutrientes (Fig. 12b). Entre as duas fases, as espécies herbáceas reptantes avançaram em direção à duna ocupando o espaço da $D$. echastophyllum retirada em 2018, o que pôde ser observado dois meses após o início dos trabalhos. Observa-se nas Figuras 12c-e que toda a área foi ocupada pelas espécies I. pes- 
caprae, Hydrocotyle bonariensis Lam (erva-capitão) e Canavalia rosea Sw (feijão-dapraia), além das espécies Remirea maritima Aueb (pinheirinho) e Cereus fernambucensis Lem (mandacaru-da-praia) em um espaço de 7-8 meses.

Mesmo com a supressão e expansão das outras espécies nativas supracitadas, inspeções são feitas periodicamente para a identificação e retirada de novas plântulas da $D$. echastophyllum e de espécies invasoras. A princípio, as inspeções se davam a cada quinze dias; com o crescimento e expansão da $I$. pes-caprae, H. bonariensis e $R$. marítima, por exemplo, a periodicidade aumentou para um mês.

\section{Parcela 3 (setor sul)}

Na parcela 3 (Fig. 8 e Figs. 13a-d), a supressão da D. ecastophyllum foi efetuada em duas fases. Junto ao caminho central (setor sul da parcela), a retirada foi feita no período 2018-2019, sendo a área trabalhada junto à Av. Litorânea e ao caminho central. Esse setor foi o primeiro a sofrer a poda em larga escala, mas, por desconhecimento das características da espécie D. ecastophyllum, ela foi feita sem a retirada das raízes horizontais, o que com a rebrota de troncos e raízes demandou refazer o trabalho (Fig. 13a). A espécie que ficou restrita nas proximidades da duna foi retirada entre maio e dezembro de 2020. Nesse setor, o trabalho é mais complexo e demanda mais tempo, devido à grande concentração de resíduos dentro da vegetação e da presença disseminada de arbustos espinhosos e, principalmente, das espécies T. catappa (amendoeira) e I. curica (campainha) (Fig. 13b). Portanto, os trabalhos ainda não foram concluídos (Figs. 13c-d). 
Revista Eletrônica Uso Público em Unidades de Conservação. Niterói, RJ. Vol. 9, no 14. 2021 http://www.periodicos.uff.br/uso_publico

Figura 12. Evolução dos trabalhos na parcela 2 com a supressão da espécie $D$. ecastophyllum e a expansão de outras espécies, em especial a I. pes-caprae, H. bonariensis e R. maritima: (a) mar-2018; (b) maio-2020; (c) out-2020; (d) maio-2021; (e) jul-2021. Setor costeiro do loteamento Orla 500, $2^{\circ}$ Distrito de Tamoios, Cabo Frio, RJ.
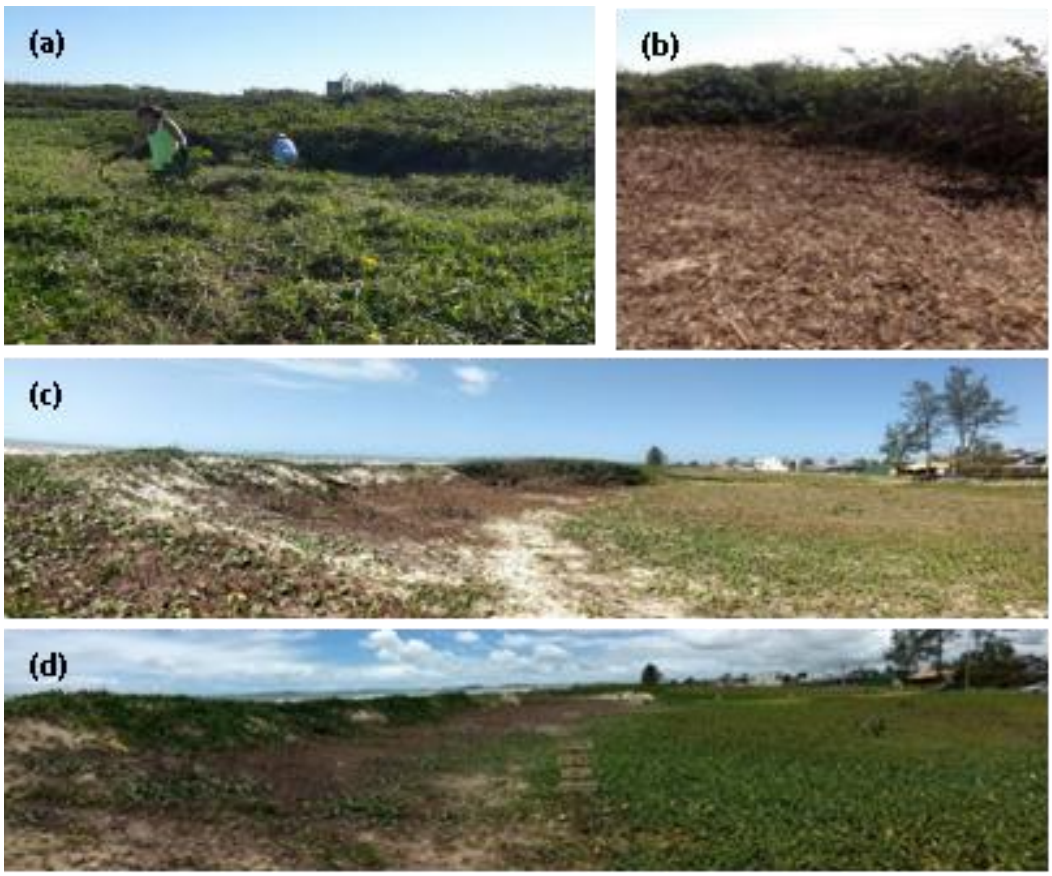

(e)

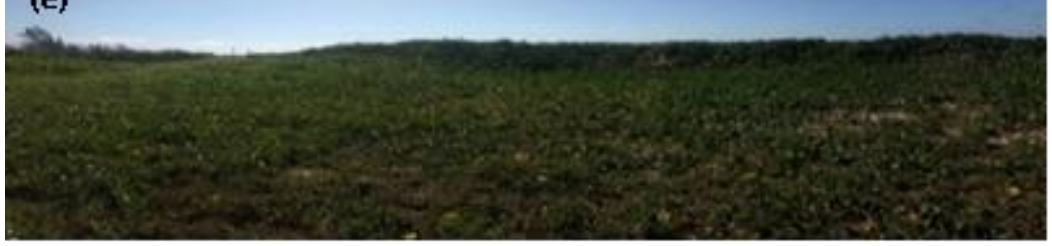

Fonte: Fotos do autor 
Figura 13. Supressão da espécie D. ecastophyllum na parcela 3 (setor sul). Nesta área, outras espécies cobrem a D. ecastophyllum e há grande acúmulo de resíduos: (a) mai-2018; (b) jul-2020; (c) nov-2020; (d) mai-2021. Setor costeiro do loteamento Orla 500, $2^{\circ}$ Distrito de Tamoios, Cabo Frio, RJ.
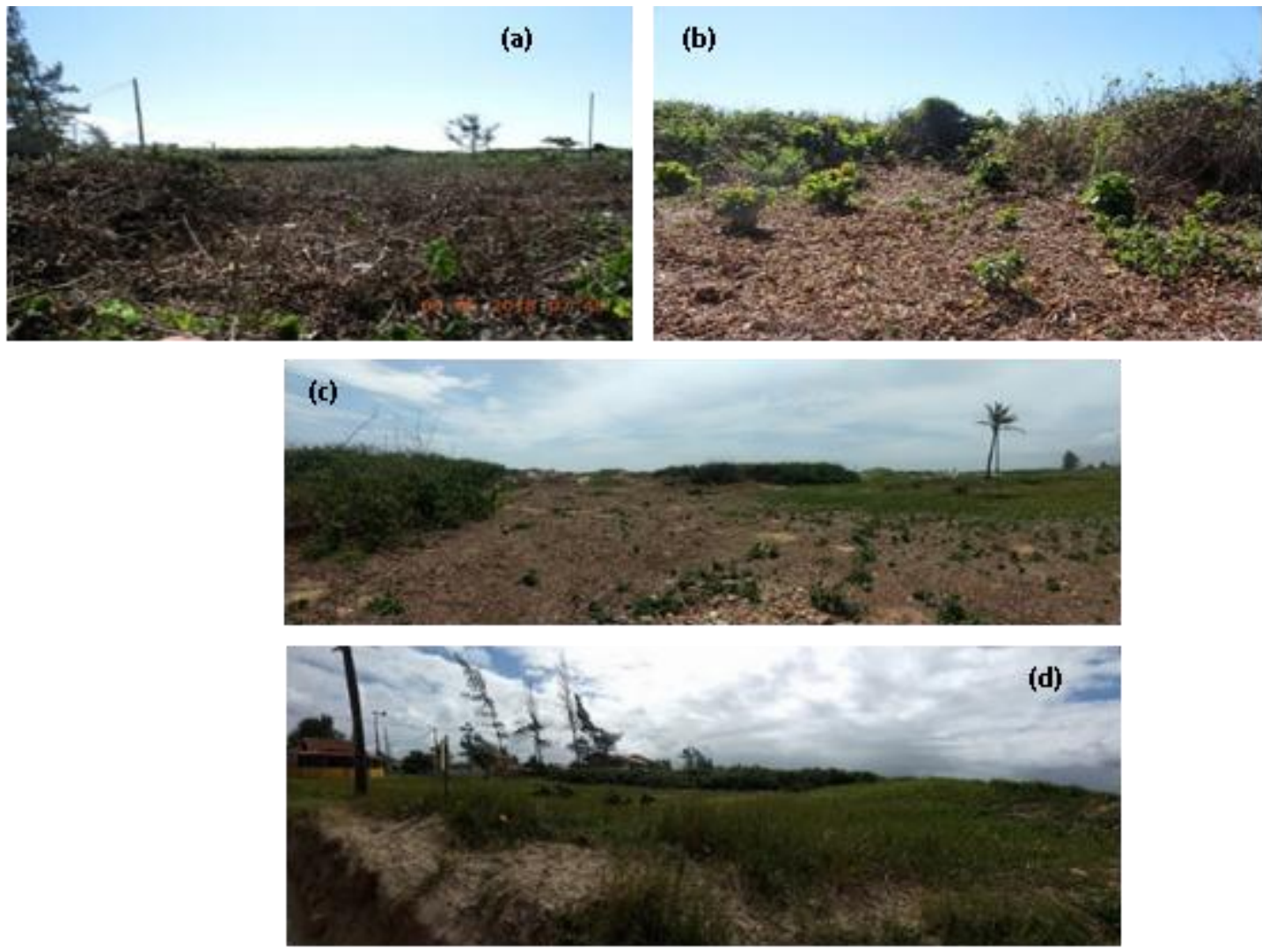

Fonte: Fotos do autor

\section{Parcela 3 (setor norte)}

Nessa parte, os trabalhos se concentraram na supressão da D. ecastophyllum e também da poda da espécie T. catappa (amendoeira) (Figs. 8 e 14a-b). A retirada da grande quantidade de folhas das amendoeiras sobre o terreno, a presença de animais peçonhentos (aranhas e cobras) e a grande quantidade de formigas demandam mais tempo e cuidado. 
Figura 14a-b. Supressão da espécie D. ecastophyllum na parcela 3 (setor norte) entre julho (a) e novembro de 2021 (b). Observa-se a sequência das amendoeiras (b). Os trabalhos seguem nesta parte da parcela. Setor costeiro do loteamento Orla 500, $2^{\circ}$ Distrito de Tamoios, Cabo Frio, RJ.
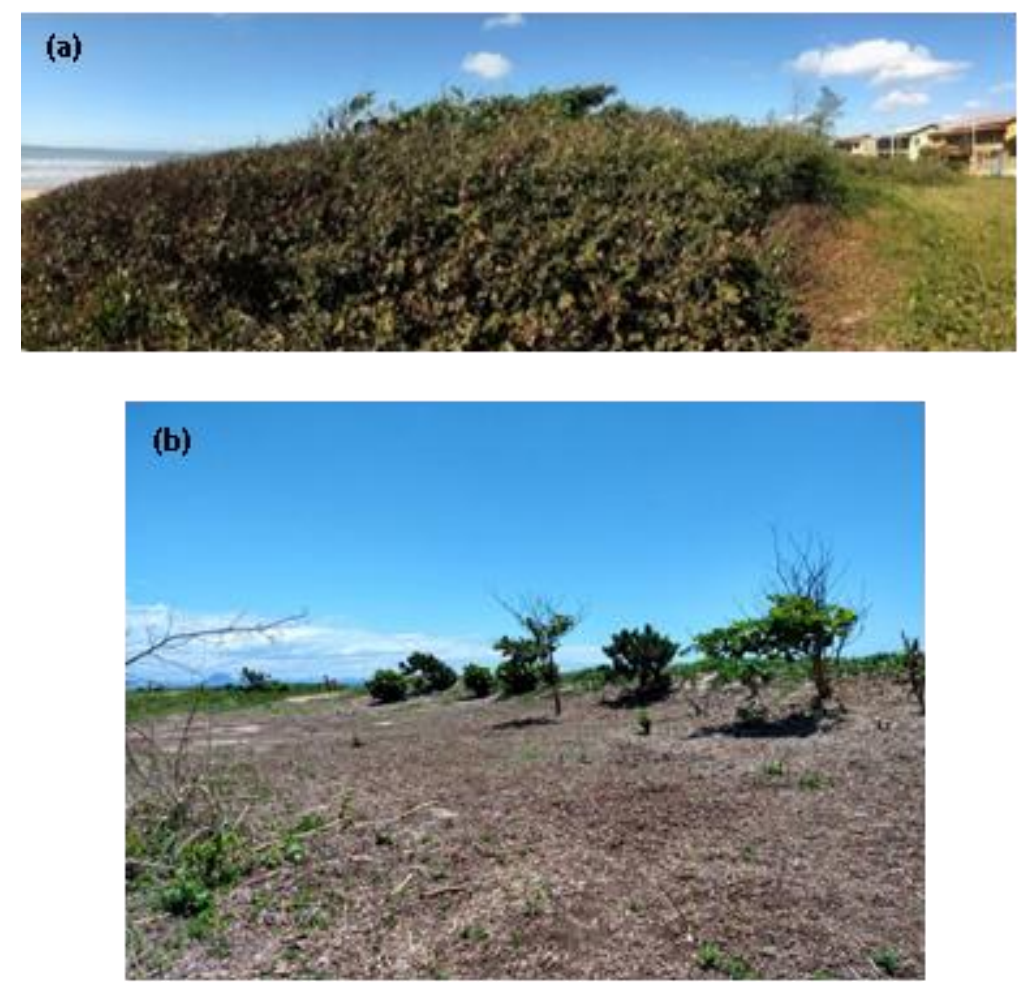

Fonte: Fotos do autor

\section{Parcelas 4 e 5}

Nestas parcelas, a supressão da espécie $D$. ecastophyllum foi total, e a exemplo da parcela 2, concentrou-se na área junto à duna entre janeiro e julho de 2021, mas as atividades tiveram seu início em 2018 (Figs. 8 e 15a-d). Inspeções a cada 10-15 dias são feitas para a identificação e retirada de plântulas da espécie $D$. ecastophyllum que germinam a partir de sementes disseminadas no setor reverso da duna. Nessas parcelas, a supressão da $D$. ecasthophyllum está permitindo, além da expansão da I. pes-caprae, $H$. bonariensis (feijão da praia) e Allagoptera arenaria (Gomes) Kuntze (guriri), o desenvolvimento de vários indivíduos da espécie C. fernambucensis (mandacaru-da-praia) e da espécie $R$. maritima (pinheirinho), antes encobertos e de menor porte. 
Figura 15. Evolução dos trabalhos nas parcelas 4 e 5 com a retirada da espécie $D$. ecastophyllum e a expansão de outras espécies, em especial a I. pes-caprae: (a) dez-2018; (b) jan-2021; (c) mai-2021; (d) out-2021. Setor costeiro do loteamento Orla 500, $2^{\circ}$ Distrito de Tamoios, Cabo Frio, RJ.
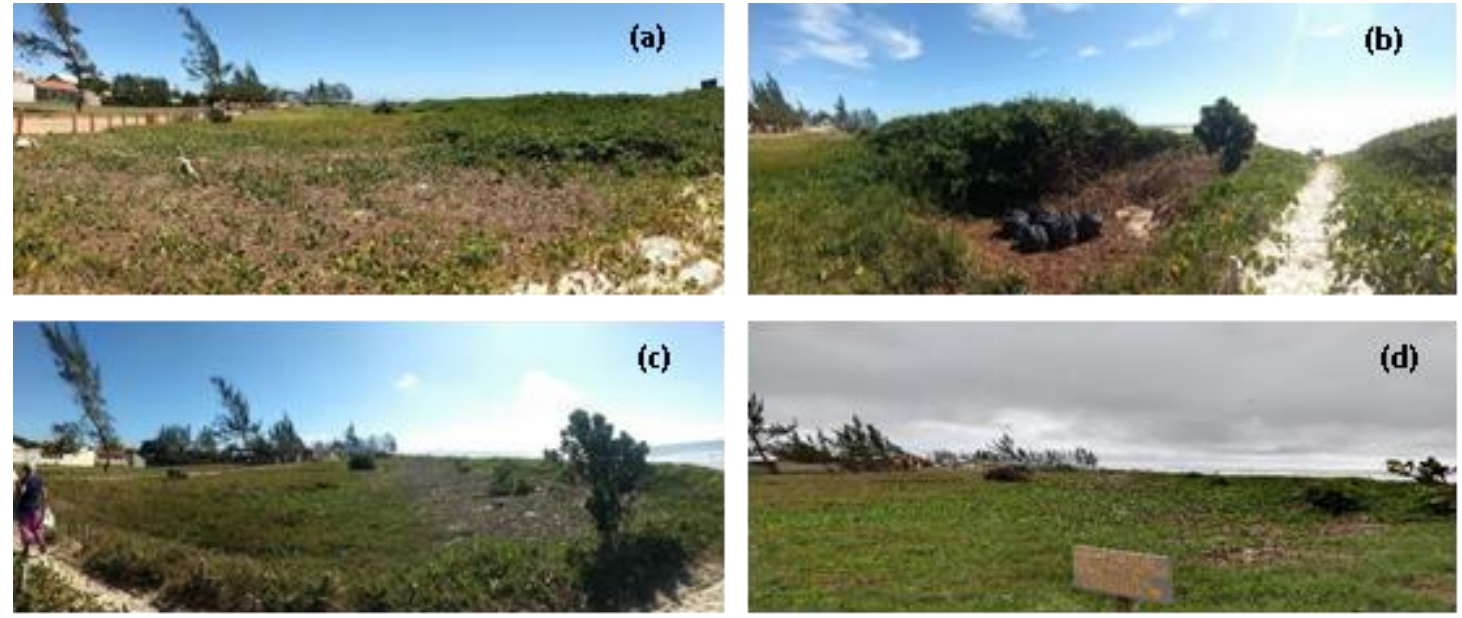

Fonte: Fotos do autor

Grande parte dos resíduos recolhidos (Fig. 16) é constituída por materiais não recicláveis, sem interesse para a cadeia recicladora, como espumas, embalagens metalizadas, fibras vegetais, cordas, cestas. Foram ainda retirados da área da vegetação monitor de computador, televisão, cadeiras de praia, cadeiras de plástico, guarda sol de praia, luminárias, bonecas, sandálias, tênis, chinelos e diversas peças de vestuário.

Os trabalhos seguirão nas parcelas 1 e 3 , o que demandará tempo, uma vez que são áreas extensas. Ademais, estão sendo observadas a expansão das espécies nativas e a estabilidade da duna. A duna está sendo gradativamente coberta, principalmente pela I. pescaprae, e apresenta-se estável ao longo de todo o período do manejo. Projeta-se a realização de um inventário de espécies da flora nas áreas antes cobertas pela $D$. ecastophyllum.

Figura 16. Lixo retirado de um setor de apenas $1 \mathrm{~m}^{2}$ coberto pela vegetação. Setor costeiro do loteamento Orla 500, $2^{\circ}$ Distrito de Tamoios, Cabo Frio, RJ.

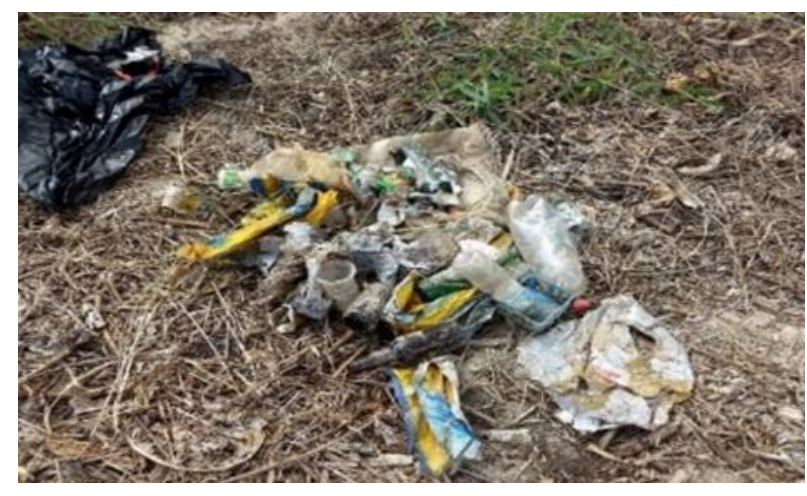

Fonte: Fotos do autor 


\section{DISCUSSÃO}

$\mathrm{Na}$ área de vegetação de restinga no Loteamento Orla 500, o perfil topográfico do terreno e o dinamismo da vegetação puderam evoluir nos setores pós-praia e reverso da duna frontal. Apesar da presença de espécies exóticas, como a casuarina e amendoeira, a recuperação gradual da vegetação de restinga ao longo da última década, acompanhada do desenvolvimento da duna frontal, oferece uma oportunidade de evolução para um estágio mais estável. No entanto, a espécie D. ecastophyllum acabou dominando a área, limitando o desenvolvimento das outras espécies nativas de restinga. Desta forma, observou-se que as manchas dominantes da espécie (SOUZA, 2016) podem atuar como moduladores da paisagem alterando não somente a composição de espécies, mas também a estrutura da paisagem (GABAY, PEREVOLOTSKY e SHACHAK, 2012).

Ficou constatado com as atividades de manejo que o seu grande crescimento em altura e seu adensamento não são compatíveis com áreas densamente ocupadas e de circulação de pessoas em direção à praia, as quais exercem forte e constante pressão ambiental, principalmente quando não há políticas públicas efetivas de controle e manejo da vegetação, de segurança e limpeza pública. Mesmo assim, em função da sua reconhecida importância na proteção contra a erosão e na recuperação de áreas degradadas (CARVALHO, 1997; MATA et al., 2014), a D. ecastophyllum foi mantida na área de entorno da saída das águas pluviais, impactada sucessivamente por eventos de fortes chuvas e da maré alta.

Não foram encontrados na literatura científica exemplos de supressão da espécie $D$. ecastophyllum como prática de manejo. Grande parte dos trabalhos publicados mostra o potencial produtivo da espécie com abelhas que produzem própolis vermelho com atividades oxidante, antimicrobiana e citotóxica para células tumorais (ALENCAR et al., 2007, MENDONÇA-MELO et al., 2017, ARAÚJO et al., 2018; CAPATINTA et al., 2020). No entanto, outros estudos indicam interações interespecíficas negativas entre a $D$. ecastophyllum e outras espécies herbáceas (CASTELLANI et al., 2004; PEIXOTO et al., 2006, SOUZA, 2010). Souza (2016), usando como exemplo a expansão da mancha dominante de D. ecastophyllum em dunas costeiras na praia de Joaquina (SC), constata que os efeitos de espécies nativas sobre outras podem ser tão agressivos quanto de espécies invasoras, tornando-se um problema para a conservação da diversidade local.

Algumas práticas autorizadas de supressão da espécie foram registradas em 2019 na cidade de Rio das Ostras, na praia de Costa Azul, tendo em vista o avanço da vegetação sobre a rua, comprometendo a trafegabilidade e a visibilidade, aumentando desta forma a insegurança local. ${ }^{2}$ Apresentando os mesmos argumentos, foi efetuada a supressão dessa espécie na orla de Matinhos, Paraná, em 2020, sem autorização ambiental e sem manejo, o

\footnotetext{
${ }^{2}$ https://www.riodasostras.rj.gov.br/rio-das-ostras-recebe-autorizacao-ambiental-para-suprimir-vegetacao-na-orla/
} 
que resultou em protestos e ações no Ministério Público. ${ }^{3}$ A ausência de manejo na retirada da espécie $D$. ecastophyllum pode aumentar os riscos de degradação da área, com a exposição do terreno às ações do vento e do mar.

A invasão de espécies exóticas pode ocorrer com a imigração de indivíduos dispersados pelo mar, vento, animais ou ação humana (ZIMMERMANN, 2012). A introdução de espécies exóticas para fins ornamentais e estabilização das dunas (ZIMMERMANN, 2012) foi uma prática comum na área. Espécies dos gêneros Acacia e Casuarina são exemplos de espécies exóticas invasoras introduzidas (RICHARDSIN e REJMÁNEK, 2011) e que estão presentes não somente na área de vegetação de restinga como também nas áreas construídas. Ao longo da área de vegetação de restinga, casuarinas podem ser observadas e, por serem tolerantes à salinidade, condições áridas e baixa fertilidade do solo (DECHOUM et al., 2015), encontraram condições para a sua expansão. No entanto, as amendoeiras (Terminalia catappa) foram encontradas em maior quantidade, mais próxima ao mar e no reverso da duna do que nas áreas edificadas, em ruas e casas para fins de sombreamento. Na restinga, vários indivíduos da espécie estavam encobertos pela D. ecastophyllum e ainda em estágio inicial de crescimento, o que infere que suas sementes foram transportadas pelo mar, uma vez que são vistas constantemente na praia, no lixo de maré (Fig. 14b). Como a área sofre a influência de correntes vindas do Norte (MUEHE et al., 2011), infere-se que as sementes possam ser transportadas por essas correntes e que a foz do rio São João também seja um vetor dispersor. Situação similar foi observada por Plucênio, Dechoum e Castellani (2013) na ilha de Santa Catarina e nas áreas de restinga do Nordeste por Fabricante et al. (2021).

Foram observados na área de entorno da espécie T. catappa, algumas já ultrapassando os $5 \mathrm{~m}$ de altura, o grande acúmulo de folhas e a ausência de espécies nativas. O sombreamento proporcionado pela copa formada por folhas largas e a produção de substâncias químicas da espécie (aleloquímicos) podem interferir na germinação de sementes, no desenvolvimento e no crescimento de raízes de outras espécies (BARATELLI et al., 2012), aumentando dessa forma a sua capacidade de invasão.

Alguns estudos associam a expansão de algumas espécies invasoras com as mudanças climáticas. Estudos de Wang et al. (2011) hipotetizaram que as crescentes temperaturas poderiam alterar os padrões da relação raiz-ramos e o potencial alelopático da I. cairica, acelerando a sua expansão invasiva (Figs. 6a-b), cobrindo extensas áreas já ocupadas pela D. ecasthopyllum. Modelos desenvolvidos por Inague, Zwiener e Marques (2021) destacam mudanças potenciais na distribuição da biodiversidade que poderiam levar à homogeneização biótica na vegetação de restinga até 2050. Somados às mudanças no uso da terra (CASTRO, ROCHA e VIEIRA, 2020) e à ausência de políticas públicas efetivas de

\footnotetext{
${ }^{3}$ https://www.plural.jor.br/noticias/vizinhanca/decreto-de-ratinho-autoriza-corte-de-vegetacao-protegida-sem-autorizacaoambiental/
} 
gestão das zonas costeiras, as tendências de elevação da temperatura e precipitação projetadas para o setor sudeste da Mata Atlântica (RAN1, 2020) podem ter impactos na regulação nos processos biológicos e químicos e, consequentemente, no desenvolvimento da vegetação. Portanto, faz-se necessária a continuidade das atividades de manejo e a ampliação dos estudos na área.

\section{CONSIDERAÇÕES E ATIVIDADES FUTURAS}

Pode-se dizer que o conflito entre uso público e uso privado da área, os sucessivos impactos da ocupação permanente e o uso turístico, muitas vezes de caráter predatório, somados à ausência do poder público quanto à orientações e ações, e os sinais de degradação visíveis da vegetação de restinga, acabaram atuando como gatilhos para as iniciativas das ações de manejo.

As atividades de manejo efetuadas na vegetação de restinga até o momento se concentraram na supressão da espécie D. ecastophyllum, monodominante na área, e de espécies invasoras como a I. cairica e T. catappa (amendoeira). Não houve plantio de nenhuma espécie nativa; as espécies herbáceas reptantes, como a I. pes-caprae já estabilizada no setor pós-praia, avançam sobre o terreno no reverso da duna e no espaço de seis meses, aproximadamente, e já cobrem boa parte da área antes ocupada pela D. ecastophyllum.

As áreas que abrigavam a $D$. ecastophyllum não sofreram ações intempéricas nem ocorreu deslocamento de areia após a sua supressão. O êxito até agora observado na supressão da espécie na área de restinga está associado a proximidade de outras espécies nativas e a rápida sucessão que se deu a partir da cobertura de biomassa da própria $D$. ecastophyllum, que protege o terreno do vento, além de conservar a umidade e nutrientes.

A supressão da espécie realiza-se desde o início de forma lenta, uma vez que a retirada das raízes dispostas horizontalmente demanda mais tempo. As atividades concentradas em duas fases, com a manutenção da $D$. ecastophyllum junto à duna no primeiro momento possibilitou a expansão das outras espécies em sua direção, e ao mesmo tempo manteve a estabilidade da duna; na fase da supressão da espécie no reverso da duna, o avanço das outras espécies nativas pôde efetuar-se em duas direções: sentido duna e sentido loteamento. Portanto, infere-se que a recuperação gradual de áreas menores seja possível e vantajosa na resolução de problemas locais. Não é recomendada, no entanto, a retirada de nenhuma espécie sem uma análise prévia das condições climáticas locais, do terreno e das áreas de entorno que proporcionem condições de regeneração da cobertura vegetal em um espaço relativamente curto de tempo. No caso da D. echastophyllum, seu sistema radicular desempenha um papel inegável na fixação de terrenos e no combate à erosão, podendo a sua retirada de forma aleatória incorrer no risco de maior deslocamento de areia, mobilidade da duna e aumento da erosão. Atenção é igualmente necessária para a rápida invasão e expansão da espécie $T$ catappa (amendoeira), pois a sua supressão requer mais esforços. 
Pode-se elencar as maiores dificuldades e desafios observados até agora nas atividades de manejo empreendidas na vegetação de restinga ao longo do Loteamento Orla 500: (1) falta de apoio técnico por parte do poder público na orientação e definição de ações norteadoras para a recuperação de áreas degradadas e manejo apropriado; (2) a pouca conscientização e envolvimento de parte de moradores e frequentadores no trabalho voluntário de manejo; (3) ausência do poder público quanto a orientação e suporte relativos à legislação e fiscalização de circulação e atividades realizadas nas áreas de entorno da vegetação, como a praia e os seus acessos, principalmente em feriados e em períodos de alta temporada; (4) falta de recursos financeiros e de pessoal para as atividades na área de vegetação de restinga.

A carência de pessoal para o trabalho e a falta de engajamento do poder público convertem as atividades de manejo na vegetação de restinga desenvolvidas até o momento em um relevante serviço de manutenção do equilíbrio ambiental e de benfeitoria à comunidade local e visitantes. Observou-se e é ressaltado que o manejo apropriado da vegetação de restinga está diretamente associado à gestão apropriada dos loteamentos. Como a vegetação de restinga encontra-se junto às áreas habitadas e de recreação, está sujeita a fortes pressões e, sem o seu manejo apropriado, pisoteio, descarte de resíduos e avanço de espécies exóticas e monodominantes podem comprometer as suas funções ambientais, atualmente tão importantes e necessárias

O trabalho de manejo segue, e é sugerida a realização de um inventário de espécies nas parcelas trabalhadas, além de estudos das possíveis relações entre a dinâmica da vegetação e as mudanças climáticas em curso, com projeções de elevação regional da temperatura e precipitação. Portanto, como proposta conservacionista, a implantação de uma unidade de conservação da natureza (UC) na Orla Sul de Tamoios (APA ou Parque Natural Municipal) seria um reconhecimento da necessidade de se promover o manejo do cinturão de vegetação de restinga que contribui efetivamente para a proteção da zona costeira dos eventos de erosão, mais constantes e intensos. Dessa forma, a criação de uma UC vem ao encontro das propostas de adequação das atividades humanas na região, com a conservação de áreas sensíveis e importantes quanto a sua prestação de serviços ambientais.

\section{REFERÊNCIAS}

ALENCAR, M.C.; OLDONI, T.L.C.; CASTRO, M.L.; CABRAL, I.S.R.; COSTA-NETO, E.S.; CURY, J.A.; ROSALEN, P.L. e IKEGAKI, M. (2007) Chemical composition and biological activity of a new type of Brazilian propolis: red propolis. J. Ethnopharmacol, v. 113, p. 278-283.

ARAÚJO, D.S.D. e ENRIQUES, R.P.B. (1984) Análise florística das restingas do Estado do Rio de Janeiro. Restingas: origens, estrutura, processos. Niterói, CEUFF. p. 159-193.

ARAÚJO, J.M.E.; SANTOS, L.; MENDONÇA-MELO, E.; DIVINO, A.; FERNANDES, R.P.M. e SCHER, R. (2018) Phenolic composition and leishmanicidal activity of red 
própolis and dalbergia ecasthoppylum (L.) Taub (Fabaceae) extracts from Sergipe, Brazil. Human and Animal Health, v. 61.

BOHER, C.B.A.; DANTAS, H.G.R.; CRONEMBERGER, F.M.; VICENS, R.S. E ANDRADE, S.F. (2009) Mapeamento da vegetação e do uso do solo no centro de diversidade vegetal de Cabo Frio, Rio de Janeiro. Rodriguésia, v. 60, n. 1, p. 001-023.

BARATELLI, T.G.; CANDIDO GOMES, A.C.; WESSJOHANN, L.A.; KUSTER, R.M. e SIMAS, N.K. (2012) Phytochemical and allelopathic studies of Terminalia catappa L. (Combretaceae). Biochemical Systematics and Ecology, v. 41, p.119-125.

BULHÕES, E.; FERNANDEZ, G.; OLIVEIRA FILHO, S.R. e PEREIRA, T.G. (2016) Coastal impacts induced by storm waves between Cabo Frio and Búzios, Rio de Janeiro, Brazil. Journal of Coastal Research, v. 75, p. 1047-1051.

CAPATINTA, G.V.C.; MEJÍA, J.A.A.; TANIMOTO, M.H.; GROPPO, M.; SARMENTO, J.C.A. e BASTOS, J.K. (2020) Dalbergia ecasthoppylum (L.) Taub. and Symphonia globulifera L.f.: The botanical sources of isoflavonoids and benzophenones in brazilian red propolis. Molecules, v. 25, n. 9.

CARTER, R.W.G. (1986) The morphodynamics of beach-ridge formation: Magilligan, Northern Ireland. Marine Geology, v. 73, n. 3-4, p. 191-432.

CARVALHO, A.M. (1997) A synopsis of the genus Dalbergia (Fabaceae: Dalbergieae) in Brazil. Brittonia, v. 49, p. 87-109.

CASTELLANI, T.T.; PEIXOTO, J.R.V. e LOPES, B.C. (2004) Variação temporal da vegetação das dunas da Praia da Joaquina, Ilha de Santa Catarina. Anais da Semana Nacional de Oceanografia, Itajaí.

CASTELLANI, T.T.; SANTOS, F.A.M. (2006) Abundância, sobrevivência e crescimento de plântulas de Ipomoea pes-caprae (L.) R. Br. (Convolvulaceae) na Ilha de Santa Catarina, SC, Brasil. Acta Botanica Brasilica, Feira de Santana, v. 20, n. 4, p. 875-885.

CASTRO, L.Q.; ROCHA, T.B. e VIEIRA, R. (2020) Mapeamneto da linha de costa e avaliação da vulnerabilidade e susceptibilidade à erosão costeira entre a foz do rio São João e a foz do rio Uma, Cabo Frio, RJ. Arq. Cien. Mar. Fortaleza, v. 53 (Especial), p. 7-24.

COE, H.H.G.; CARVALHO, C.N.; SOUZA, L.O.F. e SOARES, A. (2007) Peculiaridades Ecológicas da Região de Cabo Frio, RJ. Revista de Tamoios, ano IV, n. 2.

DAVIDSON-ARNOTT, R.; HESP, P., OLLERHEAD, J.; WALKER, I.; BAUER, B.; DELGADO-FERNANDEZ, I. e SMYTH, T. (2018) Sediment budget controls on foredune height: Comparing simulation model results with field data. Earth Surface Processes and Landforms, v. 43, n. 9, p. 1798-1810.

DECHOUM, M.; CASTELLANI, T.; ZILLER, S.; PLUCÊNIO, R.; SOUZA, V. e LOPES, J. (2015) Envolvimento comunitário e universitário na restauração da diversidade biológica. Revista Eletrônica de Extensão, ISSN 1807-0221. Florianópolis, v. 12, n. 19, p. 51-60.

DEVALL, M.S. (1987) Ecology of Ipomoea pes-caprae (Convolvulaceae) at Grand Isle, Louisiana. Proceedings of Louisiana Academy of Science, v. 50, p. 7-12. 
DOYLE, T.B.; SHORT, A.D.; RUGGIERO, P. e WOODROFFE, C.D. (2019) Interdecadal Foredune Changes along the Southeast Australian Coastline: 1942-2014. Journal of Marine Science and Engineering, v. 7. n. 6, p. 177.

FABRICANTE, J.R.; CRUZ, A.B.S.; REIS, F.M. e ALMEIDA, T.S. (2021) Biological invasion in restinga sites in northeastern Brazil. Agrarian and Biological Sciences, v. 10, n. 6, p. e48410615942, 2021. DOI: 10.33448/rsd-v10i6.15942

FERNANDEZ, G.B. e MUEHE, D.A. (1998) Influência de sedimentos fluviais na morfologia da praia e antepraia no embaiamento Rio das Ostras - Cabo Búzios - RJ. Geosul, v. 14, n. 27, p. 200-203.

GABAY, O.; PEREVOLOTSKY, A. e SHACHAK, M. (2012) How landscape modulators function: woody plant impact on seed dispersal and abiotic filtering. Plant Ecology, v. 213, p. $685-693$

HART, T.B.; HART, J.A. e MURPHY, P.G. (1989) Monodominant and species-rich forests of the humid tropics: causes for their co-occurrence. American Naturalist, v. 133, p. 613-633.

HESP, P.A. (2000) Coastal sand dunes: form and function. CDVN Technical Bulletin, v. 4, p. 28.

HESP, P.A. e WALKER, I.J. (2013) Coastal Dunes. In: JOHN F. S (Ed.). Treatise on Geomorphology. San Diego: Academic Press. p. 328-355.

HOLZER, W.; CRICHYNO, J. e PIRES, A.C. (2004) Sustentabilidade da urbanização em áreas de restinga: uma proposta de avaliação pós-ocupação. Paisagem Ambiente, v. 19, p. 49-66.

INAGUE, G.M.; ZWIENER, V.P. e MARQUES, M.C.M. (2021) Climate change threatens the woody plant taxonomic and functional diversities of the restinga vegetation in Brazil. Perspectives in Ecology and Conservation, v. 19, p 53-60.

IPCC - Inetergovernmental Panel on Climate Change. (2021) Summary for Policymakers. In: Climate Change 2021: The Physical Science Basis.

LIMA, L.A.; MACHADO, D.V.; SABINO, H. e MENEZES, J. (2020) Caracterização hidrogeoquímica e isotópica do aquífero costeiro do Distrito de Tamoios, Cabo Frio, RJ. Anuário do Instituto de Geociências, UFRJ, v. 43, n. 4, p. 218-228.

MARQUES, O.A.V. e DULEBA. V. (2004) Estação Ecológica Juréia-Itatins - Ambiente físico, flora e fauna. Editora Holos, Ribeirão Preto.

MARTIN, L.; SUGUIO, K.; DOINGUEZ, J.M.L. e FLEXOR, J.M. (2012) Geologia do Quaternário costeiro do litoral norte do Rio de Janeiro e do Espírito Santo. São Paulo, FAPESP/CPRM (Escala 1200.000 e texto explicativo).

MATA, V.P.; COSTA, M.A.P.C.; MORAIS, D.V. e CARVALHO, C.A.L. (2014) Germinação de sementes de Dalbergia ecastaphyllum (L.) Taubert sob diferentes temperaturas. Enciclopédia Biosfera, Goiânia, v. 10, n. 18, p.1832-1844.

MENDONÇA-MELO, L.; MOTA, E.; LOPEZ, B.; SAWAYA, A.; FREITAS, L.; JAIN, S.; BATISTA, M. e ARAÚJO, E. (2017) Chemical and genetic similarity between Dalbergia 
ecasthoppylum and red propolis from the Northeastern Brazil. Journal od Apicultural Research, v. 56, n. 1, p. 32-39.

MOURA, N.S.V.; MORAN, E.F.; STROHAECKER, T.M. e KUNS, A.V. (2015) A Urbanização na Zona Costeira: Processos locais e regionais e as transformações ambientais - o caso do Litoral Norte do Estado do Rio Grande do Sul, Brasil. Ciência e Natura, v. 37, n. 42 , p. 594-612.

MUEHE, D.; FERNANDEZ, G.B.; BULHÕES, E. e AZEVEDO, I.F. (2011) Avaliação da vulnerabilidade física da orla costeira em nível local, tomando como exemplo o arco praial entre Rio das Ostras e o Cabo Búzios, RJ. Revista Brasileira de Geomorfologia, v. 12, n. 2, p. $45-58$.

PEIXOTO, J.R.V.; HORN-FILHO, N.O.; CASTELLANI T.T. e OLIVEIRA, U.R. (2006) Summer variations of the morphology and the pionner vegetation of the foredune in the Santinho Beach, Santa Catarina Island, SC, Brazil. Journal of Coastal Research, v. 39, p. 622-625.

PEIXOTO, J.R.V. (2010) Interação praia-duna e sua influência sobre a vegetação de duna frontal na costa leste da ilha de Santa Catarina, SC. Tese de Doutorado, Programa de Pósgraduação em Geografia, UFSC, 175p.

PLUCÊNIO, R.M.; DECHOUM, M.S. e CASTELLANI, T.T. (2013) Invasão biológica em restinga: o estudo de caso de Terminalia catappa L. (Combretaceae). Biodiversidade Brasileira, v. 3, n. 2, p. 118-136.

RAN1 - Primeiro Relatório de Avaliação Nacional sobre Mudanças Climáticas, Base científica das mudanças climáticas. (2013). Disponível em:

$<$ http://www.pbmc.coppe.ufrj.br/index.php/pt/publicacoes/relatorios-pbmc/item/basecientifica-das-mudancas-climaticas-volume-1-completo?category_id=18>. Acessado em: 03 nov. 2021.

RICHARDSON, D.M. e REJMÁNEK, M. (2011) Trees and shrubs as invasive alien species - a global review. Diversity and Distributions, v. 17, p. 788-809.

RUGGIERO, P.; HACKER, S.; SEABLOOM, E. e ZARNETSKE, P. (2018) The role of vegetation in determining dune morphology, exposure to sea-level rise, and storm-induced coastal hazards: a US Pacific Northwest perspective. In: Barrier Dynamics and Response to Changing Climate. Springer, p. 337-361.

SOUZA, P.Z. (2010) Dinâmica espaço-temporal de Dalbergia ecastophyllum (L.) Taub. em restinga no sul do Brasil. Programa de Pós-Graduação em Ecologia, Dissertação de mestrado, Universidade Federal de Santa Catarina, 118 p.

SOUZA, P.Z. (2016) Efeitos de manchas monodominantes sobre a organização e estrutura de comunidades vegetais em restinga subtropical. Programa de Pós-Graduação em Ecologia, Tese de Doutorado, Universidade Estadual de Campinas, 105 p.

SUGUIO, K. (2003) Geologia Sedimentar. Edgard Blucher, São Paulo, 416 p.

VIEIRA, R.; MONTEZUMA, R.C.M. e VALLEJO, L.R. (2019a) Projeto de envolvimento da comunidade local para recuperação e manejo da vegetação de restinga no Setor Sul de Tamoios, Cabo Frio, RJ. In: (FILHO, J.R.F., ASHLEY, P.A., CORRÊA, M.M. (Org.). 
Educação Ambiental, Sustentabilidade e Desenvolvimento Sustentável. Contribuições para o Ensino de Graduação. Eduff, Niterói, p. 625-648.

VIEIRA, R.; CHAMBERLAIN, I.M.M. e MONTEZUMA, R.C.M. (2019b) Capacidade de carga física e qualidade recreacional das praias do setor sul do Distrito de Tamoios, Cabo Frio, RJ. Uso Público em Unidades de Conservação, v. 7, n. 11, p. 42-62.

WANG, R.L.; ZENG, R.S.; PENG, S.L.; MCHEN, B.; LIANG, X.T. e WXIN, X. (2011) Elevated temperature may accelerate invasive expansion of the liana plant Ipomoea cairica. Weed Research, v. 51, p. 574-580.

ZIMMERMANN, T.G. (2012) Contaminação das Restingas por Casuarina equisetifolia L.: Atributos biológicos que limitam à regeneração natural da vegetação. Programa de Pósgraduação em Botânica Diversidade Vegetal: Conhecer e Conservar. Instituto de Pesquisa Jardim Botânico do Rio de Janeiro. Escola Nacional de Botânica Tropical, 26 p. 